\title{
IIMIII Impact of Bridging Income Generation with Group Integrated Care (BIGPIC) on Hypertension and Diabetes in Rural Western Kenya
}

\author{
Sonak D. Pastakia, PharmD, MPH, BCPS ${ }^{1,2,3,4}$, Simon M. Manyara, BPharm, MSc ${ }^{1,2,4}$, \\ Rajesh Vedanthan, $M D, M P H^{5}$, Jemima H. Kamano, MBChB, MMed ${ }^{1,2,3}$, Diana Menya, PhD 6 , \\ Benjamin Andama, $B A^{7}$, Cleophas Chesoli, $B A^{7}$, and Jeremiah Laktabai, MBChB, MMed ${ }^{7,3,7}$ \\ ${ }^{1}$ Academic Model Providing Access To Healthcare (AMPATH), Eldoret, Kenya; ${ }^{2}$ Moi Teaching and Referral Hospital, Eldoret, Kenya; ${ }^{3}$ College of \\ Health Sciences, School of Medicine, Moi University, Eldoret, Kenya; ${ }^{4}$ College of Pharmacy, Purdue University, West Lafayette, IN, USA; ${ }^{5}$ Icahn \\ School of Medicine at Mount Sinai, New York, NY, USA; ${ }^{6}$ College of Health Sciences, School of Public Health, Moi University, Eldoret, Kenya: \\ ${ }^{7}$ Webuye District Hospital, Webuye, Kenya.
}

BACKGROUND: Rural settings in Sub-Saharan Africa (SSA) consistently report low participation in noncommunicable disease (NCD) treatment programs and poor outcomes.

OBJECTIVE: The objective of this study is to assess the impact of the implementation of a patient-centered rural NCD care delivery model called Bridging Income Generation through grouP Integrated Care (BIGPIC).

DESIGN: The study prospectively tracked participation and health outcomes for participants in a screening event and compared linkage frequencies to a historical comparison group.

PARTICIPANTS: Rural Kenyan participants attending a voluntary NCD screening event were included within the BIGPIC model of care.

INTERVENTIONS: The BIGPIC model utilizes a contextualized care delivery model designed to address the unique barriers faced in rural settings. This model emphasizes the following steps: (1) find patients in the community, (2) link to peer/microfinance groups, (3) integrate education, (4) treat in the community, (5) enhance economic sustainability and (6) generate demand for care through incentives.

MAIN MEASURES: The primary outcome is the linkage frequency, which measures the percentage of patients who return for care after screening positive for either hypertension and/or diabetes. Secondary measures include retention frequencies defined as the percentage of patients remaining engaged in care throughout the 9month follow-up period and changes in systolic (SBP) and diastolic blood pressure (DBP) and blood sugar over 12 months.

KEY RESULTS: Of the 879 individuals who were screened, $14.2 \%$ were confirmed to have hypertension, while only $1.4 \%$ were confirmed to have diabetes. The implementation of a comprehensive microfinancelinked, community-based, group care model resulted in $72.4 \%$ of screen-positive participants returning for

Electronic supplementary material The online version of this article (doi:10.1007/s11606-016-3918-5) contains supplementary material, which is available to authorized users.

Received April 18, 2016

Revised September 8, 2016

Accepted October 26, 2016

Published online December 5, 2016 subsequent care, of which $70.3 \%$ remained in care through the 12 months of the evaluation period. Patients remaining in care demonstrated a statistically significant mean decline of $21 \mathrm{mmHg}$ in SBP [95 \% CI (13.9 to 28.4), $P<0.01$ ] and $5 \mathrm{mmHg}$ drop in DBP [95 \% CI (1.4 to 7.6), $P<0.01]$.

CONCLUSIONS: The implementation of a contextualized care delivery model built around the unique needs of rural SSA participants led to statistically significant improvements in linkage to care and blood pressure reduction.

KEY WORDS: diabetes; hypertension; sub-Saharan Africa; rural; microfinance; incentives; portable care; agriculture.

$\mathrm{J}$ Gen Intern Med 32(5):540-8

DOI: $10.1007 / \mathrm{s} 11606-016-3918-5$

(C) Society of General Internal Medicine 2016

\section{INTRODUCTION}

Low- and middle-income countries (LMICs) are facing an increasing burden of non-communicable diseases (NCDs). Patients in LMICs with NCDs such as diabetes and hypertension are generally characterized by very poor outcomes and limited prospects for a healthy life due in large part to limited access to reliable healthcare services. Due to their chronic nature, NCDs strain the already scarce resources of healthcare systems and families in LMICs. ${ }^{1}$

While substantial concern for NCDs centers on the impact of increasing urbanization in Sub-Saharan Africa (SSA), the growing burden of diabetes and hypertension in rural areas is largely neglected. The manifestation of NCDs in rural LMICs occurs in the relative absence of sedentary lifestyles and caloric over-nutrition. ${ }^{2}$ This is further complicated by the limited access to care for NCDs; for instance, less than $5 \%$ of patients in rural SSA have access to care for hypertension. ${ }^{3}$ In response to the growing awareness of the increasing importance of NCD care in rural settings, the Academic Model Providing Access to Healthcare (AMPATH) has set out to expand care access to address these pressing challenges in the western Kenya catchment we serve. ${ }^{4}$ However, in our setting and throughout SSA, low linkage (coming for care after screening positively for a disease) and retention to care 
(remaining in care after initially joining care) contribute to the inadequate control of NCDs in rural SSA. ${ }^{5-12}$ In Kenya, over $50 \%$ of the population earns less than $\$ 1$ per day, and user fees for rural outpatient NCD care have been shown to adversely affect access to care. ${ }^{1314}$ With $75 \%$ of the population living in rural areas and experiencing these economic realities in subSaharan Africa in 2014, contextualized solutions for addressing the barriers to care for underserved rural populations must be found. ${ }^{15}$

It is within this context that the Bridging Income Generation with GrouP Integrated Care (BIGPIC) program was created. BIGPIC uses an integrated approach that capitalizes and builds on AMPATH's existing infrastructure and years of experience in managing patients with HIV/AIDS throughout western Kenya. ${ }^{16,17}$ In order to increase uptake of care for rural settings, six pillars of intervention were emphasized: (1) find patients in the community (hold screening events within the communities patients reside in), (2) link to peer/ microfinance groups, (3) integrate education, (4) treat in the community, (5) enhance economic sustainability and (6) generate demand for care through incentives. Here, we describe the linkage frequencies, retention frequencies and clinical outcome measures for hypertension and diabetes resulting from the BIGPIC pilot intervention.

\section{METHODS}

\section{Setting}

AMPATH is a partnership among Moi University, Moi Teaching and Referral Hospital, and a consortium of North American universities led by the Indiana University School of
Medicine. The history, organizational structure and health programs of AMPATH have been described elsewhere. ${ }^{16-18}$

We implemented the pilot BIGPIC initiative in a rural area called Sinoko, which has an estimated population of 21,207 people, covers an area of $30.2 \mathrm{~km}$ and is approximately $7 \mathrm{~km}$ from the nearest paved road. We screened individuals residing within a 3-km radius of a $\mathrm{MOH}$-supported dispensary. ${ }^{19,20}$ Farming is the main economic activity for residents in this area.

The screening was conducted between November 2012 and April 2013 with different locations within Sinoko being targeted. Individuals who showed up for the screening were included within the data analysis for this evaluation. The only participants who were excluded from this study were those that refused to participate in any of the healthcare screening activities. All other participants were included within this evaluation.

\section{Description of Intervention}

BIGPIC utilizes an approach designed to combine six different pillars of service delivery into a single comprehensive system focused on sustainably delivering healthcare services as illustrated in Figure 1 and briefly described below. Additional details of the intervention can be found within the supplementary appendix available online.

Find Patients in the Community. Community health workers (CHW) received stipends from the program to make the community aware of the upcoming NCD screening and wealth generation activity that was planned through the implementation of the BIGPIC program by informing village elders and chiefs, distributing fliers and making announcements at community gatherings. The BIGPIC activities were conducted

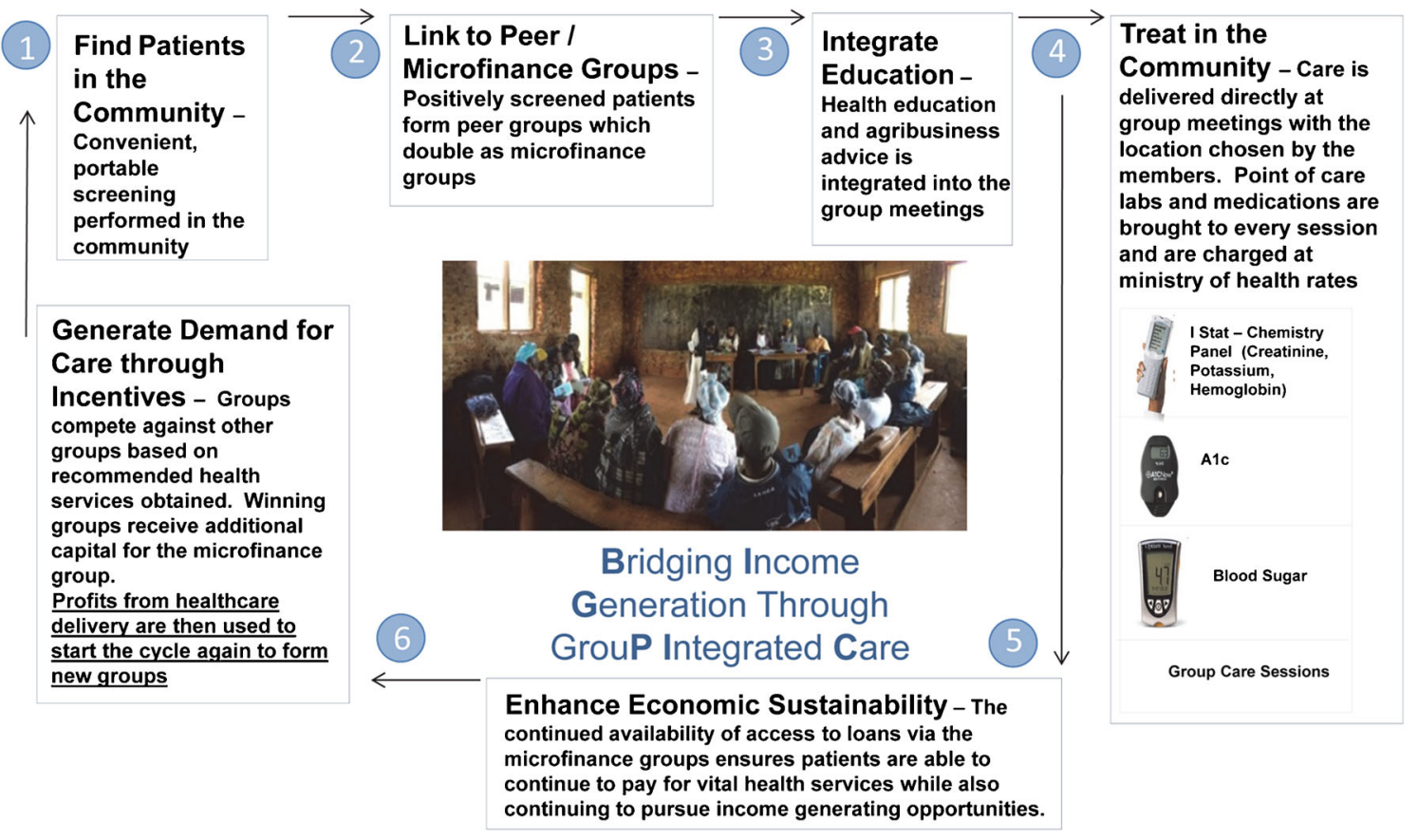

Fig. 1 BIGPIC model of care 
through portable service delivery within the community and involved both microfinance experts and NCD-trained staff. The NCD-trained staff performed point-of-care screening using an automatic sphygmomanometer cuff to screen for hypertension and a portable point-of-care blood glucose meter to screen for diabetes. Patients who were confirmed to be screen positive were informed by local CHWs of the need for future follow-up that could be received by attending group meetings.

Link to Peer/Microfinance Groups. CHWs were utilized to inform all the positively screened patients of the date, time and location of the initial education session where all the detailed aspects of the intervention were explained with a special emphasis on microfinance. CHWs would communicate information to these individuals primarily by meeting them at routinely held local meetings or by visiting their houses as they typically reside within the community they serve. Participants were also contacted by phone if these other methods were not adequate. All participants then received guidance on forming self-selected peer microfinance groups of 10-30 members, which included patients who were confirmed to have hypertension and/or diabetes along with members of the community who wanted access to microfinance services. The members of the microfinance group would decide on a meeting point for these microfinance meetings among themselves. Typical meeting points included houses of members, churches and schools.

Integrate Education. In addition to receiving training on establishing microfinance groups, participants received health education on appropriate management of their condition, ways to improve agricultural output and the importance of saving money to prepare for future life events.

Treat in the Community. After receiving basic health education including information on the ministry of health standard charges to be expected for health care services provided in the community, the groups were visited on a monthly basis by trained healthcare providers during their microfinance meetings. These providers brought point-of-care laboratory tests and medications and provided consultations to all patients wanting to access care. Examples of charges patients paid for services include $\sim \$ 1.00$ USD for consultation with a clinician, $\sim \$ 1.00$ USD per point-of-care glucose test and $\sim \$ 0.01$ USD per hydrochlorothiazide $50 \mathrm{mg}$ tablet.

Enhance Economic Sustainability. The economic component of the project was focused on establishing Village Savings and Loan Association (VSLA) microfinance associations that were designed to assist communities with mobilizing and managing their own savings, providing interest-bearing loans to members without a requirement for collateral. While the core members of the group were all patients with hypertension and/or diabetes, additional members, regardless of health status, were allowed to join the groups up to a maximum of 30 members per group. Through the VSLAs, patients were able to access affordable loans and get business advice from program officers who were also responsible for ensuring groups accurately monitored and reported all financial transactions. At the end of each year, all members received a proportionate share of the savings and interest accumulated over the course of the year with their proportion being determined by their relative contribution to savings. The savings and interest generated from this activity were described descriptively.

Generate Demand for Care through Incentives. During the initial education sessions, the groups received instructions on the incentives that could be earned through the management of their health condition. Incentives were awarded at two levels of participation: the group level whereby the top three groups with the most improved process and outcome metrics received rewards in the form of additional capital for the microfinance group and at the individual level whereby each participant attaining pre-set goals received a reward, regardless of whether their group won or not. Within these scoring criteria, each patient was evaluated on their performance on basic process metrics including attendance at regularly scheduled clinic visits, purchase of medication refills and payment for a recommended laboratory or radiological test. Clinical outcomes were also evaluated; however, these received much lower weighting in the overall score than the aforementioned process metrics. Any individuals scoring higher than $80 \%$ in this scoring criterion received a cash prize of $\sim \$ 5$; those meeting $100 \%$ receiving $\sim \$ 10$ and a cell phone valued at $\sim \$ 15$. For the group prizes, the group coming in first place received $\sim \$ 10$ per group member, second place received $\sim \$ 7.50$ per group member and third place received $\sim \$ 5$ per group member. These incentive payments were paid from the revenue generated from care delivery and then paid out to members during the microfinance activities. The remaining revenue generated from payments for care was used to screen new patients and initiate the model in additional sites.

\section{DATA COLLECTION}

All data were collected on standardized paper screening and care forms and then entered electronically for subsequent analysis. The name, estimated age, location of residence, systolic (SBP)/diastolic blood pressure (DBP) measurements, random blood glucose measurements and $\mathrm{HbA1c}$ (when available) were recorded for each participant. In screening sites where there was access to working scales, height and weight were captured; however, those data were not reported here as they were not performed for all participants.

\section{ANALYSIS}

The progression of participants through the five different phases of BIGPIC are illustrated in Fig. 2: phase 1, initial 


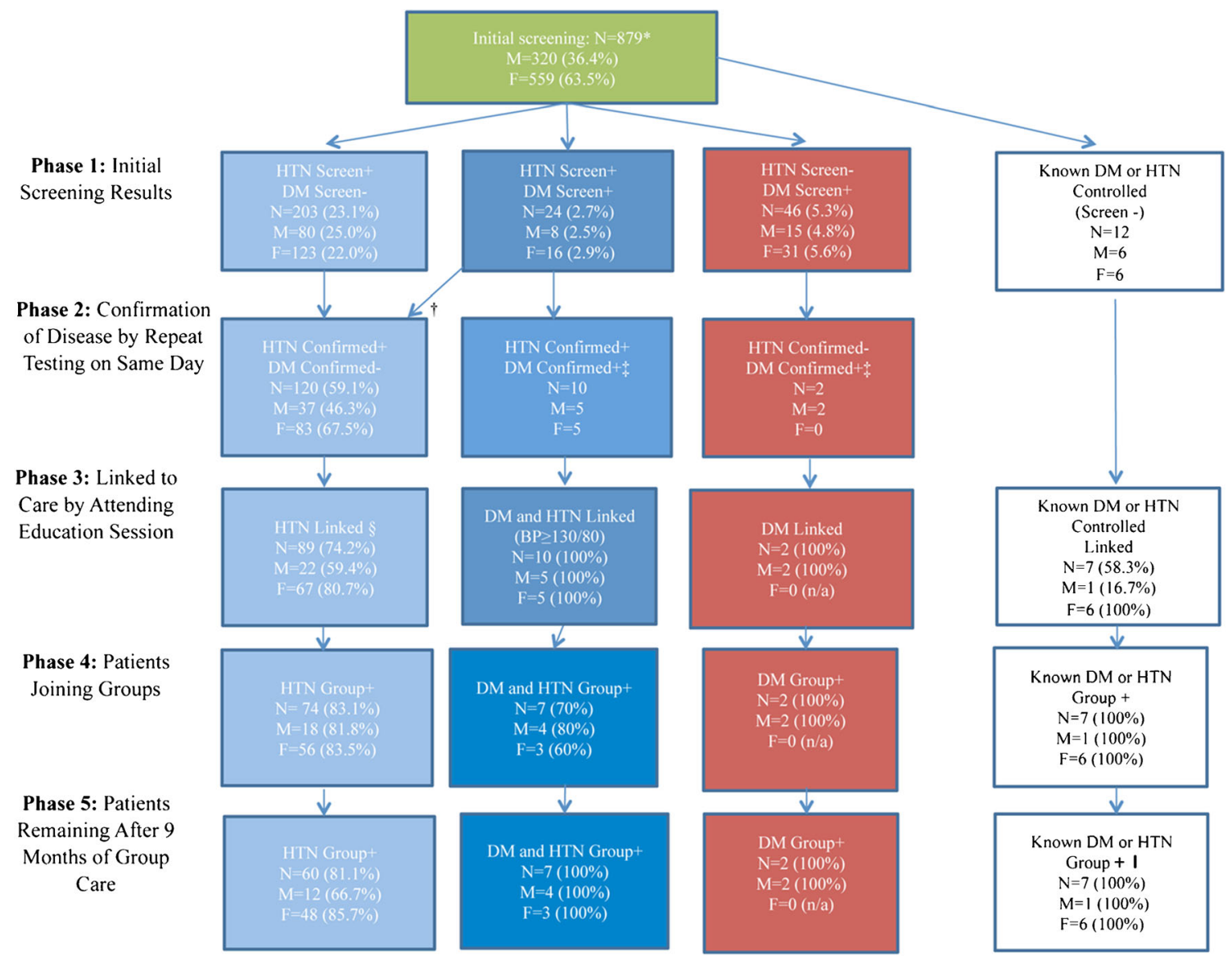

Fig. 2 Flow chart of participant progression through the linkage and retention cascade. $M=$ male participants, $F=$ female participants, $R B S=$ random blood sugar, HTN = hypertension, DM = diabetes mellitus, HTN Screen+ defined as SBP $\geq 150 \mathrm{mmHg}$ or DBP $\geq 90 \mathrm{mmHg}$, DM Screen+ defined RBS $\geq 7 \mathrm{mmol} / \mathrm{l}(126 \mathrm{mg} / \mathrm{dl})$. *Fifteen individuals refused blood sugar screening; ${ }^{\dagger} 8$ patients were HTN screen+ and DM screen- on confirmation; ${ }^{\$} 32$ patients were screened for DM via point-of-care HbA1c testing when available with 9 becoming positive; ${ }^{\$} 8$ patients did not have an elevated blood pressure upon returning to the groups and were excluded from further care assessments; ${ }^{7}$ new female patients with known disease joined the groups over the course of the intervention but were not included within this figure as they were not identified via screening

screening; phase 2, confirmation of disease by repeat testing on the same day; phase 3, linked to care by attending initial care education session; phase 4 , patients joining groups; phase 5 , patients remaining in care after 9 months of group care.

Descriptive statistics were used to describe the primary outcome of linkage frequencies among patients who screened positive for either diabetes or hypertension. A positive linkage event was defined as having an individual who screened positive for hypertension and/or diabetes and then returned to a subsequent group meeting. An overall linkage frequency to return for care was calculated by dividing the number of screen-positive individuals with a positive linkage event by the total number of screen-positive individuals. In addition, the linkage frequency among four different possible categories - hypertension only, diabetes and hypertension, diabetes only, or previously known history of diabetes and/or hypertension on treatment - was also calculated. The linkage frequency of male versus female was also calculated using the chi-square test. In order to compare linkage frequencies with the BIGPIC approach relative to the more traditional model of healthcare delivery, Fischer's exact test was utilized to compare the likelihood of linking to care in the current strategy compared to the previously published historical comparison group. ${ }^{5}$ In the historical group, a similar community-based screening strategy was utilized to identify individuals with hypertension and/or diabetes within an area located in the same county approximately $10 \mathrm{~km}$ away from the location studied within this pilot study. In the historical control, all screen-positive patients were instructed to return to a stationary Ministry of Health facility for confirmation and subsequent care as opposed to the community-based model utilized within the current pilot. In both models, patients were informed of pre-specified days where confirmation testing would be available for free in the 1-month period following the screening. The same definition for a linkage event was used in both studies. In addition to Fischer's exact test, a regression analysis controlling for known potential confounders such as age and gender was also performed.

For the secondary measure assessing clinical outcomes related to blood pressure, the paired $t$ test was used to compare the baseline SBP and DBP results with the results obtained after 12 months from the initial screening activity. The mean 
blood pressure results were also calculated at 3-month intervals and compared to the baseline result. In addition to this clinical outcome, the percentage of patients retained within care was calculated by assessing the number of patients who remained in care (phase 5) after joining the group care model (phase 3). For diabetes-related measurements, descriptive statistics were used as there was an insufficient sample size to perform meaningful statistical analysis.

All statistical analyses were performed using Stata Statistical Software package ${ }^{\circledR}$ (StataCorp, College Station, TX), and a $p$-value $<0.05$ was deemed to be statistically significant.

This analysis was approved by the Institutional Research and Ethics Committee based at Moi University School of Medicine and the Indiana University Purdue University Indianapolis Institutional Review Board.

\section{RESULTS}

A total of 879 individuals agreed to screening for chronic diseases with the majority (63.6\%) of individuals being female.

An additional 17 participants were completely excluded from any analysis as their age was not recorded on the screening registers. All enrollees agreed to blood pressure screening; however, 15 patients refused the finger stick required for blood glucose screening but were still included within the analysis. The demographic characteristics and screening results for the population can be found in Table 1 with participants having an average age of 43 . To better understand the progression of patients through this model, Fig. 2 provides an illustration of the flow of participants as they transitioned through the different phases as described below. The initial screening results from phase 1 found $23.1 \%$ were screen-positive for hypertension, $2.7 \%$ for diabetes and hypertension and $5.3 \%$ for diabetes. Upon completion of repeat testing for hypertension in phase 2, 120 (59.1\%) screen-positive hypertension patients were confirmed with a second elevated blood pressure reading. In total, 125 patients $(14.2 \%)$ were found to be

Table 1 Demographic Characteristics and Screening Results for the Overarching Population

\begin{tabular}{|c|c|c|c|}
\hline Characteristic & $\begin{array}{l}\text { Male } \\
(N=320)\end{array}$ & $\begin{array}{l}\text { Female } \\
(N=559)\end{array}$ & $\begin{array}{l}\text { Entire } \\
\text { population } \\
(N=879)\end{array}$ \\
\hline Mean age, years (SD) & $44.6(19.1)$ & $41.4(16.8)$ & $42.6(17.7)$ \\
\hline $\begin{array}{l}\text { Mean SBP mmHg } \\
\text { (SD) }\end{array}$ & $\begin{array}{l}137.2 \\
(20.5)\end{array}$ & $\begin{array}{l}136.0 \\
(23.5)\end{array}$ & $136.4(22.5)$ \\
\hline $\begin{array}{l}\text { Mean DBP mmHg } \\
\text { (SD) }\end{array}$ & $78.8,11.8$ & $79.9,12.4$ & $79.3,12.0$ \\
\hline $\begin{array}{l}\text { Mean RBS mmol/l } \\
(\mathrm{mg} / \mathrm{dl}),[\text { SD mmol/l] }\end{array}$ & $\begin{array}{l}5.17 \\
(93.54) \\
{[1.86]}\end{array}$ & $\begin{array}{l}5.24 \\
(94.42) \\
{[1.72]}\end{array}$ & $\begin{array}{l}5.21(93.80), \\
{[1.77]}\end{array}$ \\
\hline
\end{tabular}

SBP systolic blood pressure; DBP diastolic blood pressure; $R B S$ random blood sugar

${ }^{a}$ Fifteen patients refused the point-of-care blood glucose test. Of these, seven were male and eight were female hypertensive when including individuals who were known to already have hypertension. In the diabetes screen-positive arms, the lack of availability of point-of-care HbA1c cartridges impeded the study from providing confirmatory diagnoses on the day of the screening for 38 patients. Despite being informed of the availability of free fasting blood sugar checks, only two patients returned for confirmation at a later date with only one of them being confirmed to have diabetes. Of the 32 participants who received confirmation on the day of screening via point-of-care $\mathrm{HbAlc}, 9$ were confirmed to have diabetes with 4 patients having markedly elevated $\mathrm{HbA} 1 \mathrm{cs}$ above $13 \%$. While a true estimation of diabetes prevalence is not possible with the limited follow-up, $1.4 \%$ of the population was confirmed to have diabetes with ten patients having diabetes with hypertension and two patients with only diabetes.

In the primary linkage analysis in phase $3,72.4 \%$ of the patients with disease linked to the initial group care education session with linkage frequencies of 74.2, 100, 100 and $58.3 \%$ for patients with hypertension, diabetes and hypertension, diabetes alone and previously known disease, respectively. Women demonstrated a statistically significantly higher linkage frequency to care with $82.3 \%$ compared to $60.0 \%$ of men $[\mathrm{OR}=4.06,95 \% \mathrm{CI}(1.91-8.65), P<0.01]$ linking to the groups.

In the comparison of linkage frequencies with the historical control, there was a statistically significant, nearly three-fold higher likelihood of patients linking to care in the BIGPIC model compared to the traditional facility-based care model [unadjusted $\mathrm{OR}=2.94,95 \% \mathrm{CI}(1.47-5.88), P<0.01$ and adjusted $\mathrm{OR}=2.63,95 \% \mathrm{CI}(1.28-5.26), P<0.01]$. The differences in linkage and the prevalence of disease for men and women in the BIGPIC model and traditional facility-based care model in the historical control can be seen in Fig. 3a and b.

In the analysis of the care cascade after attendance at this initial group care meeting (phase 3), 90 out of 108 (83.3\%) patients joined microfinance groups and began to receive monthly portable care in the community (phase 4). Of those 90 patients from phase $4,76(84.4 \%)$ remained within the care model throughout the 9 months of group care (phase 5). In analyzing the retention of the patients who initially linked to care (phase 3 ) and then followed up with care over the remaining 9 months of the evaluation (phase 5), we found 76 out of 108 participants $(70.3 \%)$ remained in care throughout the intervention.

The analysis of the blood pressure data for the patients who were retained throughout the intervention revealed a statistically significant decline at 3 months from enrollment, which persisted throughout the remaining period of evaluation for the intervention. After 12 months of enrollment (9 months of group care), patients demonstrated a statistically significant mean decline of $21 \mathrm{mmHg}$ in SBP [95 \% CI (13.9 to 28.4), $P<0.01]$ and a statistically significant mean decline of $5 \mathrm{mmHg}$ drop in DBP [95 \% CI (1.4 to 7.6), $P<0.01$ ] as seen in Fig. 4 and Table 2. 
a

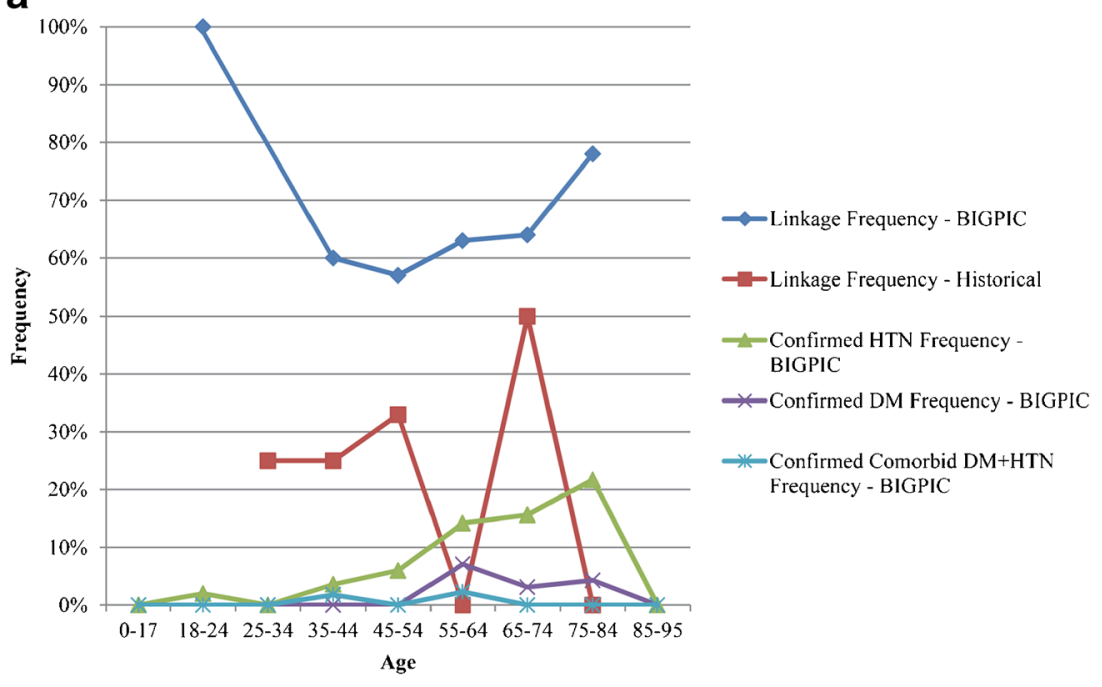

b

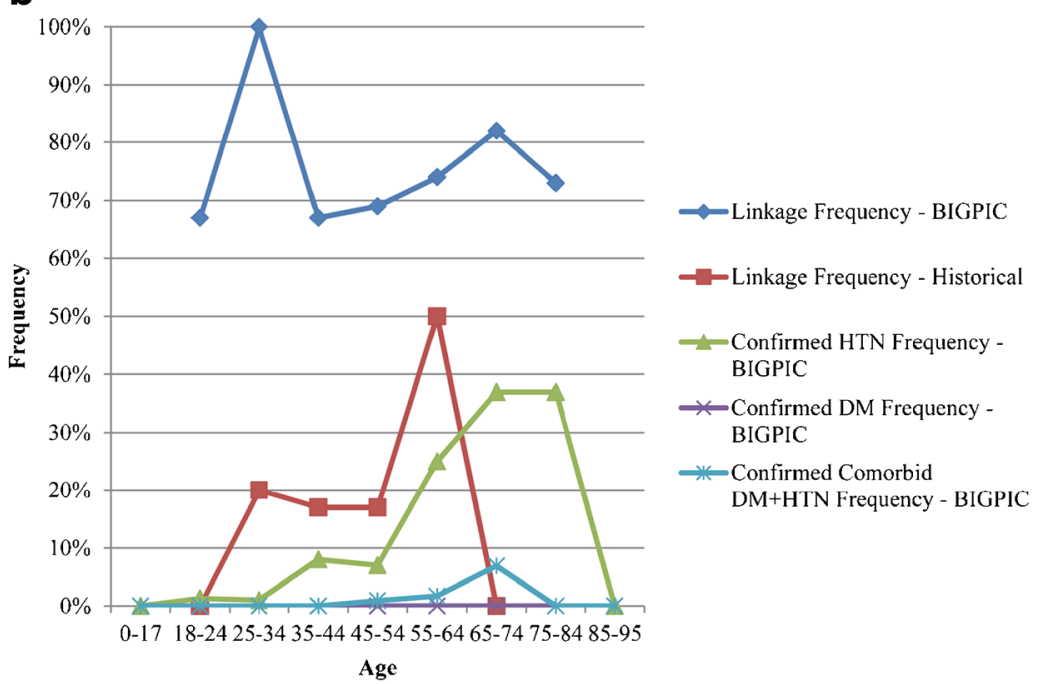

Fig. 3 a Men. b Women. DM = diabetes mellitus, HTN = hypertension. a and b Linkage frequencies and prevalence of hypertension and diabetes for men and women for hypertension and diabetes in the BIGPIC model and traditional facility-based model. $* P<0.05$ via two-sided paired $t$ test compared to baseline screening result

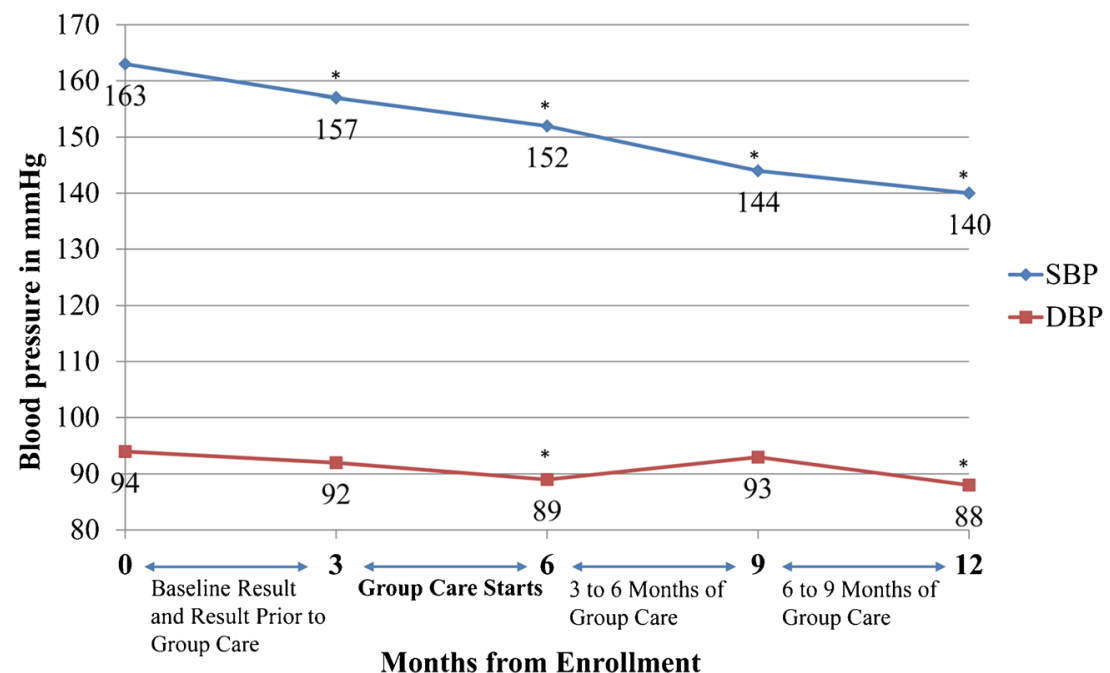

Fig. 4 Blood pressure trends throughout the care cascade. $\mathrm{SBP}=$ systolic blood pressure in $\mathrm{mmHg}, \mathrm{DBP}=$ diastolic blood pressure in $\mathrm{mmHg}$. $* P<0.05$ via two-sided paired $t$ test compared to baseline screening result 
Table 2 Blood Pressure Trends Throughout the Care Cascade Among People Attending the Initial Screening

\begin{tabular}{|c|c|c|c|c|c|c|c|c|c|c|}
\hline \multirow{3}{*}{$\begin{array}{l}\text { Number of } \\
\text { available } \\
\text { results at } \\
\text { each interval } \\
\text {-All } \\
\text {-Women } \\
\text {-Men }\end{array}$} & \multicolumn{2}{|c|}{ Screening } & \multicolumn{2}{|c|}{3 Month } & \multicolumn{2}{|c|}{6 Month } & \multicolumn{2}{|c|}{9 Month } & \multicolumn{2}{|c|}{12 Month } \\
\hline & & & & & & & & & & $\begin{array}{l}7 \\
3 \\
4\end{array}$ \\
\hline & $\begin{array}{c}\text { Mean } \\
\text { SBP } \\
\mathrm{mmHg} \\
(95 \% \mathrm{CI})\end{array}$ & $\begin{array}{c}\text { Mean } \\
\text { DBP } \\
\text { mmHg } \\
(95 \% \mathrm{CI})\end{array}$ & $\begin{array}{c}\text { Mean } \\
\text { SBP } \\
\text { mmHg } \\
(95 \% \mathrm{CI})\end{array}$ & $\begin{array}{c}\text { Mean } \\
\text { DBP } \\
\text { mmHg } \\
(95 \% \mathrm{CI})\end{array}$ & $\begin{array}{c}\text { Mean } \\
\text { SBP } \\
\mathrm{mmHg} \\
(95 \% \mathrm{CI})\end{array}$ & $\begin{array}{c}\text { Mean } \\
\text { DBP } \\
\mathrm{mmHg} \\
(95 \% \mathrm{CI})\end{array}$ & $\begin{array}{c}\text { Mean } \\
\text { SBP } \\
\text { mmHg } \\
(95 \% \mathrm{CI})\end{array}$ & $\begin{array}{c}\text { Mean } \\
\text { DBP } \\
\mathrm{mmHg} \\
(95 \% \mathrm{CI})\end{array}$ & $\begin{array}{c}\text { Mean } \\
\text { SBP } \\
\text { mmHg } \\
(95 \% \mathrm{CI})\end{array}$ & $\begin{array}{c}\text { Mean } \\
\text { DBP } \\
\text { mmHg } \\
(95 \% \mathrm{Cl})\end{array}$ \\
\hline All & $\begin{array}{l}163 \\
(158-169)\end{array}$ & $\begin{array}{l}94 \\
(91-97)\end{array}$ & $\begin{array}{l}157 \\
(152-162)\end{array}$ & 92 & $\begin{array}{l}152 \\
(147-157)\end{array}$ & 89 & 144 & 93 & 140 & $(85-91)$ \\
\hline $\begin{array}{l}p \text {-Value* } \\
\text { Females }\end{array}$ & $\begin{array}{l}165 \\
(160-171)\end{array}$ & $\begin{array}{l}95 \\
(92-98)\end{array}$ & $\begin{array}{l}0.04 \\
157 \\
(151-163)\end{array}$ & $\begin{array}{l}0.25 \\
94 \\
(90-97)\end{array}$ & $\begin{array}{l}<0.01 \\
151 \\
(146-157)\end{array}$ & $\begin{array}{l}0.04 \\
90 \\
(87-92)\end{array}$ & $\begin{array}{l}<0.01 \\
143 \\
(138-148)\end{array}$ & $\begin{array}{l}0.64 \\
93 \\
(90-96)\end{array}$ & $\begin{array}{l}<0.01 \\
140 \\
(135-145)\end{array}$ & $\begin{array}{l}<0.01 \\
85 \\
(85-92)\end{array}$ \\
\hline Males & $\begin{array}{l}157 \\
(145-169)\end{array}$ & $\begin{array}{l}90 \\
(86-94)\end{array}$ & $\begin{array}{l}157 \\
(147-167)\end{array}$ & $\begin{array}{l}86 \\
(82-89)\end{array}$ & $\begin{array}{l}152 \\
(140-163)\end{array}$ & 87 & $\begin{array}{l}146 \\
(135-158)\end{array}$ & $\begin{array}{l}91 \\
(85-96)\end{array}$ & $\begin{array}{l}139 \\
(130-148)\end{array}$ & $\begin{array}{l}84 \\
(77-91)\end{array}$ \\
\hline
\end{tabular}

SBP systolic blood pressure; DBP diastolic blood pressure

*Paired t test comparing screening result to results at different time intervals

For the ten patients with diabetes, the initial median random blood sugar and $\mathrm{HbAlc}$ seen at baseline were $8.9 \mathrm{mmol} / \mathrm{l}$ $(160.4 \mathrm{mg} / \mathrm{dl})$ and $10.8 \%$, respectively. After 6 months, the median random blood sugar was $8.5 \mathrm{mmol} / \mathrm{l}(153.2 \mathrm{mg} / \mathrm{dl})$ and $\mathrm{HbAlc}$ was $10 \%$. Among the four patients with markedly elevated HbAlcs above $13 \%$, all experienced at least a 2 percentage point drop in their $\mathrm{HbAlc}$ over the course of the intervention.

Over the course of the year, the microfinance activities of the groups resulted in a total accumulated savings of $\$ 6,616.85$ with dividend interest payments totaling $\$ 3,120.40$ (47.2\%), which was all paid out at the end of the year among the 167 participants from the community with and without chronic disease.

A total of 32 patients were awarded for achieving individual targets with 4 patients achieving a score of $100 \%$ and 28 patients achieving a score between 80 and $100 \%$. The top three groups were also awarded and received the financial payment during their microfinance activities.

\section{DISCUSSION}

Through the screening activities within the BIGPIC care delivery model, $14.2 \%$ were found to have hypertension and $1.4 \%$ were found to have diabetes. The implementation of a comprehensive microfinance-linked, communitybased, group care model resulted in $72.4 \%$ of screenpositive participants returning for subsequent care, and $70.3 \%$ of the confirmed diabetes/hypertension patients remained in care through the 9 months of group care. Patients remaining in care demonstrated a statistically significant 21-mmHg drop in SBP and 5-mmHg drop in DBP after 9 months of receiving group care.
Compared to the much lower linkage frequencies of $31 \%$ seen with the traditional facility-based care model in the same community, ${ }^{5}$ this model was highly effective in attracting patients to receive chronic disease care. The observed frequency of linkage dramatically surpasses what is typically seen for chronic diseases throughout SSA. ${ }^{6,7,21}$ In addition to the patients incorporated within this care model from screening activities, the model was also able to attract additional patients over the course of implementation as six patients with known hypertension and one patient with known diabetes joined the groups without being part of the initial screening activity. These patients became aware of the availability of the BIGPIC care model by word of mouth from other members of the community; however, their data were not included within the analysis.

While the primary interest of this investigation was to assess the frequencies of patients linking to care, the assessment of patients throughout the care cascade illustrates the sustained beneficial impact of this model on all aspects of care. The 21-mmHg mean decline in SBP illustrates the dramatic reductions in blood pressure that can be realized through the provision of care utilizing the BIGPIC model. The success of this model was evident across the entire care cascade as patients demonstrated a statistically significant reduction in SBP at all periods of evaluation after the initial screening. This includes a significant reduction even after patients received only groupbased education in the first 3 months prior to the delivery of community-based care. The immediate and sustained success further reinforces the efficacy of peer-based group education, especially among women, as seen within multiple other studies. ${ }^{22-25}$

Of equal importance is the access to capital and financial liquidity that participants receive through the microfinance component of this model, as it not only 
improves their ability to pay for their healthcare but also promotes income-generating activities that help reduce the overarching effects of poverty. Poverty and lack of finances have been described as dominant barriers to care-seeking and transportation in this setting. ${ }^{26}$ Despite charging standard government-approved charges for all services, this model was able to achieve higher linkage frequency than the $58 \%$ linkage frequency seen for HIV patients receiving fully subsidized HIV care within the AMPATH program. ${ }^{27}$

While the study was able to meet its primary objective of comprehensively assessing linkage frequencies, it did have several key limitations. With the limited resources and infrastructure available in LMICs, a nonstandard screening approach relying on point-of-care blood sugar and point-of-care $\mathrm{HbAlc}$ measurements was utilized rather than the recommended venous-based screening. Standardized procedures were used in performing all clinical tests; however, there were inherent limitations with accuracy with performing Hbalc testing in the field along with the concerns over accuracy when used for African patients. ${ }^{28}$ While there was only a documented prevalence of $1.4 \%$ for confirmed diabetes among the individuals screened for diabetes in this study, this is most likely an underestimate as many participants failed to return for confirmation during the times when point-of-care $\mathrm{HbA} 1 \mathrm{c}$ tests were not available on the day of screening. The other main limitation was the use of a convenience sample rather than a random sample, which could introduce bias. In addition, the analysis used a historical linkage frequency as the comparator. While this approach is not ideal, both interventions were performed in locations less than $15 \mathrm{~km}$ from each other and used similar methodologies for defining linkage. To address these limitations, we are currently implementing a much more rigorous cluster-randomized trial of the BIGPIC intervention. ${ }^{29}$

\section{CONCLUSION}

As LMICs continue to face an overwhelming burden of non-communicable diseases, contextualized and potentially impactful approaches such as the BIGPIC model must be thoroughly investigated to justify rapid scaleup. Instead of focusing investigations only on clinical outcome measures, investigations must also address the underlying health system barriers that prevent patients from accessing care in the first place. By demonstrating a much higher linkage frequency and superior reductions in blood pressure than traditional care delivery models relying on stationary facilities, this initiative has the potential to dramatically alter the current reality that patients with chronic diseases in LMICs face. The BIGPIC model represents a much needed departure from the donor dependent, facility-based models that are typically utilized with limited success in rural SSA settings. With the inclusion of long-term, patient-driven financing strategies, the BIGPIC model of care represents a readily scalable program that could be adapted to rural settings found throughout LMICs. Efforts to broadly scale this model up are currently underway, and there is a focused effort on determining which components of this model are responsible for the improvements in care.

Acknowledgments: This research was supported by the President's Emergency Plan for AIDS Relief through the US Agency for International Development under the terms of Cooperative Agreement No. AID-623-A-12-0001. The contents of this article are the sole responsibility of AMPATH and do not necessarily reflect the views of USAID or the US government. This project was also made possible by the Purdue University Global Policy Research Institute and the Indiana Clinical and Translational Sciences Institute, funded in part by grant no. UL1 TROO1108 from the National Institutes of Health, National Center for Advancing Translational Sciences, Clinical and Translational Sciences Award. The authors thank Abbott for providing glucose testing supplies and the Abbott Fund for providing financial support for this effort. They also thank Eli Lilly and Co. for donating insulin and providing seed funding to support the authors' overarching work in diabetes.

Rajesh Vedanthan is supported by the Fogarty International Center under Award No. KO1 TW 009218-05 and the National Heart, Lung, and Blood Institute under Award No. R01HL125487. The content is solely the responsibility of the authors and does not necessarily represent the official views of the National Institutes of Health.

An earlier version of aspects of this study were presented in poster format at the American Diabetes Association Annual meeting in San Francisco in June 2014 and at the International Diabetes Federation World Diabetes Congress meeting in Vancouver in December 2015

Corresponding Author: Sonak D. Pastakia, PharmD, MPH, BCPS; Academic Model Providing Access To Healthcare (AMPATH), Eldoret, Kenya (e-mail: spastaki@purdue.edu).

\section{Compliance with Ethical Standards:}

Conflicts of Interest: Pastakia, Sonak D previously served as a consultant for Abbott for work unrelated to this project.

The remaining authors declare that they do not have a conflict of interest

\section{REFERENCES}

1. Johnson T. Global action on non-communicable diseases. Council on Foreign Relations. 2011. CFR.org. Accessed 10 Dec 2015.

2. Mbanya JC, Motala AA, Sobngwi E, Assah FK, Enoru ST. Diabetes in sub-Saharan Africa. Lancet (London, England). 2010;375(9733):22542266. doi:10.1016/s0140-6736(10)60550-8.

3. Kayima J, Wanyenze RK, Katamba A, Leontsini E, Nuwaha F. Hypertension awareness, treatment and control in Africa: a systematic review. BMC Cardiovasc Disord. 2013;13:54. doi:10.1186/1471-2261-13-54.

4. Vedanthan R, Kamano JH, Bloomfield GS, Manji I, Pastakia S, Kimaiyo SN. Engaging the entire care cascade in western Kenya: a model to achieve the cardiovascular disease secondary prevention roadmap goals. Glob Heart. 2015;10(4):313-317. doi:10.1016/j.gheart. 2015.09.003.

5. Pastakia SD, Ali SM, Kamano JH, Akwanalo CO, Ndege SK, Buckwalter VL, et al. Screening for diabetes and hypertension in a rural low income setting in western Kenya utilizing home-based and community-based strategies. Glob Health. 2013;9:21. doi:10.1186/ 1744-8603-9-21. 
6. Bovet P, Gervasoni JP, Mkamba M, Balampama M, Lengeler C, Paccaud F. Low utilization of health care services following screening for hypertension in Dar es Salaam (Tanzania): a prospective population-based study. BMC Public Health. 2008;8:407. doi:10.1186/1471-2458-8-407.

7. Gessler N, Labhard ND, Stolt P, Manga E, Balo JR, Boffolo A, et al. The lesson of monsieur nouma: effects of a culturally sensitive communication tool to improve health-seeking behavior in rural Cameroon. Patient Educ Couns. 2012;87(3):343-350. doi:10.1016/j.pec.2011.11.007.

8. Magadza C, Radloff SE, Srinivas SC. The effect of an educational intervention on patients' knowledge about hypertension, beliefs about medicines, and adherence. Res Soc Adm Pharm: RSAP. 2009;5(4):363375. doi:10.1016/j.sapharm.2009.01.004

9. Mathenge W, Foster A, Kuper H. Urbanization, ethnicity and cardiovascular risk in a population in transition in Nakuru, Kenya: a population-based survey. BMC Public Health. 2010;10:569. doi:10. 1186/1471-2458-10-569.

10. Labhardt ND, Balo JR, Ndam M, Manga E, Stoll B. Improved retention rates with low-cost interventions in hypertension and diabetes management in a rural African environment of nurse-led care: a clusterrandomised trial. Tropical Med Int Health: TM IH. 2011;16(10):12761284. doi:10.1111/j.1365-3156.2011.02827.x.

11. van de Vijver SJ, Oti SO, Agyemang C, Gomez GB, Kyobutungi C. Prevalence, awareness, treatment and control of hypertension among slum dwellers in Nairobi, Kenya. J Hypertens. 2013;31(5):1018-1024. doi:10.1097/HJH.Ob013e32835e3a56.

12. Hendriks ME, Rosendaal NT, Wit FW, Bolarinwa OA, Kramer B, Brals D, et al. Sustained effect of health insurance and facility quality improvement on blood pressure in adults with hypertension in Nigeria: a population-based study. Int $\mathrm{J}$ Cardiol. 2016;202:477-484. doi:10. 1016/j.ijcard.2015.09.036.

13. Kankeu HT, Saksena $\mathbf{P}, \mathbf{X u} \mathbf{K}$, Evans DB. The financial burden from non-communicable diseases in low- and middle-income countries: a literature review. Health Res Pol Syst. 2013;11(1):1-12. doi:10.1186/ 1478-4505-11-31

14. UNICEF. Kenya at a glance. 2014. http://www.unicef.org/kenya/overview_4616.html. Accessed 11 Oct 2016.

15. World Bank Agricultural and Rural Development. World Bank. 2015 http://data.worldbank.org/topic/agriculture-and-rural-development. Accessed 11 Oct 2016.

16. Einterz RM, Kimaiyo S, Mengech HN, Khwa-Otsyula BO, Esamai F, Quigley F, et al. Responding to the HIV pandemic: the power of an academic medical partnership. Acad Med: J Assoc Am Med Coll. 2007;82(8):812-818. doi:10.1097/ACM.0b013e3180cc29f1.

17. AMPATH Kenya. 2015. http://www.ampathkenya.org/. Accessed 11 Oct 2016.

18. Bloomfield GS, Kimaiyo S, Carter EJ, Binanay C, Corey GR, Einterz RM, et al. Chronic noncommunicable cardiovascular and pulmonary disease in sub-Saharan Africa: an academic model for countering the epidemic. Am Heart J. 2011;161(5):842-847. doi:10.1016/j.ahj.2010.12.020.
19. eHealth-Kenya. Sinoko dispensary. 2015. http://www.ehealth.or.ke/facilities/facility.aspx?fas=16127. Accessed 11 Oct 2016 .

20. eHealth-Kenya. Webuye hospital. 2015. http://ehealth.or.ke/facilities/ facility.aspx?fas=16161. Accessed 11 Oct 2016.

21. Kotwani P, Balzer L, Kwarisiima D, Clark TD, Kabami J, Byonanebye D, et al. Evaluating linkage to care for hypertension after communitybased screening in rural Uganda. Tropical Med Int Health: TM IH. 2014;19(4):459-468. doi:10.1111/tmi.12273.

22. Park PH, Wambui CK, Atieno S, Egger JR, Misoi L, Nyabundi JS, et al. Improving diabetes management and cardiovascular risk factors through peer-Led self-management support groups in Western Kenya. Diabetes Care. 2015;38(8):e110-e111. doi:10.2337/dc15-0353.

23. Khabala KB, Edwards JK, Baruani B, Sirengo M, Musembi P, Kosgei RJ, et al. Medication adherence clubs: a potential solution to managing large numbers of stable patients with multiple chronic diseases in informal settlements. Tropical Med Int Health: TM IH. 2015;20(10):1265-1270. doi:10.1111/tmi.12539.

24. Edelman D, Fredrickson SK, Melnyk SD, Coffman CJ, Jeffreys AS, Datta S, et al. Medical clinics versus usual care for patients with both diabetes and hypertension: a randomized trial. Ann Intern Med. 2010;152(11):689-696. doi:10.7326/0003-4819-152-11-20100601000001.

25. Quinones AR, Richardson J, Freeman M, O'Neil ME, Kansagara D. VA evidence-based synthesis program reports. Group visits focusing on education for the management of chronic conditions in adults: a systematic review. Washington (DC): Department of Veterans Affairs; 2012.

26. Naanyu V, Vedanthan R, Kamano JH, Rotich JK, Lagat KK, Kiptoo P, et al. Barriers influencing linkage to hypertension care in Kenya: qualitative analysis from the LARK hypertension study. J Gen Intern Med. 2016;31(3):304-314. doi:10.1007/s11606-0153566- 1 .

27. Genberg BL, Naanyu V, Wachira J, Hogan JW, Sang E, Nyambura M, et al. Linkage to and engagement in HIV care in western Kenya: an observational study using population-based estimates from home-based counselling and testing. The Lancet HIV. 2(1):e20-e6. doi:10.1016/ S2352-3018(14)00034-4

28. Kirk JK, D'Agostino RB Jr, Bell RA, Passmore LV, Bonds DE, Karter AJ, et al. Disparities in HbAlc levels between African-American and nonHispanic white adults with diabetes: a meta-analysis. Diabetes Care. 2006;29(9):2130-2136. doi:10.2337/dc05-1973.

29. Clinicaltrials.gov. Bridging Income Generation With Group Integrated Care (BIGPIC) [NCTO2501746]. 2016. Accessed 11 Oct 2016.

30. Chobanian AV, Bakris GL, Black HR, Cushman WC, Green LA, Izzo JL $\mathbf{J r}$, et al. The seventh report of the joint national committee on prevention, detection, evaluation, and treatment of high blood pressure: the JNC 7 report. JAMA. 2003;289(19):2560-2572. doi:10.1001/jama. 289.19.2560. 